\title{
ANÁLISIS EXPLORATORIO DE LA FUNCIONALIDAD DE LAS PÁGINAS WEB DE LOS VIÑEDOS DEL PRIORAT: EL CASO DE LAS BODEGAS DE LA RUTA DEL VINO DE LA DENOMINACIÓN DE ORIGEN DE CALIDAD PRIORAT
}

\author{
Raquel Camprubí \\ Núria Galí \\ Facultad de Turismo. Universidad de Girona \\ raquel.camprubi@udg.edu, nuria.gali@udg.edu
}

Numerosas regiones, con economías basadas en la agricultura, requieren de herramientas para el desarrollo y la gestión de sus recursos, con el fin de obtener ingresos adicionales a los generados por su actividad principal. En este sentido, son habituales las actividades vinculadas al turismo. El enoturismo (o turismo de vino), por ejemplo, se considera una de estas actividades apropiada para promover zonas rurales y aumentar su competitividad.

El caso de la Denominación de Origen de Calidad (DOC) Priorat, una de las regiones vinícolas españolas más reconocidas internacionalmente, sigue esta dinámica. El Patronato de Turismo del Priorat se ha esforzado en crear una ruta del vino con el objetivo de impulsar la industria vitivinícola en esta región catalana.

En otro sentido, Internet se ha convertido en una herramienta fundamental tanto para la gestión como para la promoción de este tipo de actividades, debiniendo un poderoso instrumento de comunicación y de difusión de todo tipo de productos y destinos turísticos.

En este artículo se analiza el contenido y la usabilidad de las páginas web de las bodegas y viñedos miembros de la Ruta del Vino del Priorat. La ruta incluye dos denominaciones de origen de calidad, la DOC Priorat y la DOC Montsant. En el momento del análisis (2011) la ruta cuenta con un total de 25 bodegas de la DOC Priorat y 10 bodegas de la DOC Montsant, es decir solo una cuarta parte de las bodegas de la región. Nuestro análisis se centra en las 25 bodegas de la DOC Priorat. De entre estas 25 bodegas solo 21 disponen de página web activa ( $80 \%$ del total). 
La investigación se realiza durante los meses de octubre y noviembre de 2011 y se basa en el estudio y análisis de 22 indicadores clasificados en tres categorías, siguiendo el método expuesto por diversos autores como Amaro, Barroco y Antures (2010); Begalli, Codurri y Gaeta (2008); Bruwer (2003); Doolin et al. (2002); Mills y Morrison (2003); Morrison y col. (1999); Pérez- Bustamante (2010); Velikova, Wilcox y Dood (2011). Las tres categorías son:

a. Información relativa a la empresa, sus productos y la ruta. Esta sección incluye aspectos tales como la disponibilidad de la información en diferentes idiomas, información de contacto, mapa de ubicación, historia de la compañía, información relativa al producto (el vino), ventas online, boletines, premios recibidos, fotografías y vídeos, cuestiones éticas, uso de las redes sociales y referencias a la ruta del vino.

b. Información relativa a la usabilidad del sitio web. En especial, la funcionalidad del navegador de uso del sitio web, disponibilidad de botón de retorno y motor de búsqueda, y visibilidad del mapa web.

c. Información relativa a la promoción de la ruta, de su entorno turístico inmediato y su capacidad para crear productos turísticos. Es decir, nos ha interesado estudiar la relación de las bodegas con el turismo local. En este sentido, se analiza la información turística disponible en cada una de las páginas web de las bodegas; así como los enlaces a la Oficina de Información Turística, enlaces a empresas de alojamiento, restauración, atracciones turísticas, enlaces a otras bodegas socias de la ruta y; por último, la información sobre los productos turísticos creados por la propia bodega.

Estos indicadores nos dan acceso a un completo estudio de las estrategias online que utilizan las bodegas, así como del uso que hacen de las TIC y sus implicaciones en la ruta del vino del Priorat.

Los resultados obtenidos demuestran un nivel muy bajo de compromiso con la Ruta del Vino por parte de las bodegas miembro (de hecho, en ninguna de las páginas web de estas bodegas se indica que son miembros de la ruta, ni hay ninguna referencia a la misma) y un cierto desinterés o ignorancia en el uso de Internet como instrumento de comunicación y distribución de su producto enoturístico (solo el $25 \%$ de las bodegas informa sobre la posibilidad de visitar sus instalaciones o de la oferta de actividades turísticas que disponen). Esta falta de interés general se explica por el hecho de que las bodegas consideran que el turismo es una actividad secundaria a su actividad principal (la producción de vino) y, en definitiva, no lo perciben como parte también de su trabajo. De hecho, la mayoría de los estudios empíricos centrados en la evaluación de páginas web de bodegas, como el de Stevens y Burns (2005) en Nueva Zelanda, Velikova et al. (2011) en Estados Unidos, o Amaro et al. (2010) en Portugal, coinciden con este resultado. Esto contrasta, sin embargo, con la información que aparece en la página web oficial de la Ruta del Vino del Priorat, donde se indica claramente que es posible visitar prácticamente la totalidad de las bodegas y se incluye información detallada sobre las actividades turísticas que se pueden realizar en dichas bodegas miembros de la ruta. 
Fruto del análisis de los 22 indicadores clasificados en las tres categorías expuesta anteriormente se desperenden los siguientes resultados:

\section{a) En referencia a la Información relativa a la empresa, sus productos y la ruta}

Un aspecto positivo es que la mayoría de páginas web (85\%) se encuentran en varios idiomas. El 70\% de webs estan en inglés, además de catalán y español, y el $15 \%$ restante ofrecen información en cuatro o más idiomas (catalán, español, inglés, francés y/o alemán). Solo el 15\% de las páginas web están únicamente en catalán y castellano. La situación en este sentido es relativamente buena, pues ello contribuye a la captación de los mercados internacionales.

También es un aspecto positivo que en todas las páginas web se facilita algún tipo de información de contacto, pues ello permite que el turista potencial pueda contactar directamente con la empresa. En la mayoría de los casos $(90 \%)$ se trata del número de teléfono y la dirección; en el $85 \%$ de las páginas web además se facilita un número de fax; y también el $85 \%$ de bodegas proporciona una dirección de correo electrónico. Menos habitual es el número de empresas (45\%) que proporciona un formulario de contacto en la misma web. También es apropiado incluir información sobre cómo llegar a la bodega. En este sentido, el $70 \%$ de webs ofrecen un mapa de localización. Curiosamente uno de los miembros, a pesar de incluir en su web un enlace a un mapa de situación, éste no está activado.

Un tercer aspecto positivo de estas páginas web es que la gran mayoría (90\%) aportan información detallada sobre los vinos que producen, así como los tipos de uva utilizada, el proceso de producción, degustación, etc. Además, el 85\% de las bodegas también explican la historia de la compañía. De hecho es evidente, por la precisión y detalle de esta información, que las empresas están muy interesadas en la promoción de su actividad principal; en cambio, la poca información existente en referencia al producto enoturístico que ofrecen estas bodegas (visitas guiadas, degustación, cursos, actividades de enoturismo o turismo en la zona de los alrededores) reafirma el poco interés que tienen en la promoción de su actividad complementaria. A pesar de que estas webs proporcionan mucha información sobre la empresa y su producto, solo en el $30 \%$ de ellas es posible comprar online. Un resultado sorprendente cuando es evidente que cada bodega debería estar interesada en la venta de sus productos online, como una oportunidad de negocio más. En definitiva, se trata de páginas muy estáticas, que funcionan mayormente como escaparate y que no se usan como canal de ventas.

En cuanto a galerías de fotos se refiere, el $55 \%$ de las empresas tenía un enlace en las web para fotografías. Sin embargo, en referencia al tema vídeos, solo una bodega dispone de un vídeo de YouTube en su sitio web. Disponer de una galería de fotos y vídeos en las páginas web es una técnica eficaz de comercialización, ya que añade atractivo visual, hace que la web sea más animada, y se puede mostrar la bodega, los viñedos, sus productos y servicio.

Entre los aspectos más negativos, en referencia a esta primera categoría, destaca el incipiente uso que hacen estas bodegas de las redes sociales. El reciente y rápido crecimiento de las redes sociales (Facebook, Twitter, Linkedin, ...) demuestra que hoy en día son una herramienta de comunicación esencial para llegar a un público mucho más amplio y diverso. 
Sin embargo, solo el $20 \%$ de los miembros de la ruta utilizan las redes sociales. La red más usada es Facebook (15\% de los miembros tienen un enlace de Facebook en su página web).

Finalmente, cabe destacar que son muy pocas las bodegas que disponen de boletines de noticias o un newsletter club (20\%) o que ofrecen información sobre cuestiones éticas (15\%) y de consumo responsable (solo una bodega hace referencia al tema).

\section{b) En referencia a la Información relativa a la usabilidad del sitio web}

Con el fin de determinar la capacidad de uso de la página web de cada miembro, se analizaron de acuerdo con Miranda y Bañefil (2004) y Pérez-Bustamante (2010) cuatro aspectos diferentes: navegabilidad, mapa del sitio web, motor de búsqueda y botón de retorno.

La mayoría de los sitios web son muy estáticos, muy sencillos de usar y disponen de información muy básica. Del análisis se desprende que el $85 \%$ son de fácil navegabilidad, y solamente el $15 \%$ de webs presentan problemas o dificultades en este aspecto. De hecho, esta facilidad de uso queda justificada por el hecho que solo el $15 \%$ tiene un mapa del sitio y el $20 \%$ un botón de retorno.

El aspecto más negativo sin embargo es la falta de motor de búsqueda. Solo el $20 \%$ de páginas web disponen de este elemento. Este es un aspecto relevante ya que permite al usuario buscar información sobre un tema de interés durante la navegación por la página web de la bodega.

\section{c) En referencia a la Información relativa a la ruta, a su entorno turístico inmediato y su capacidad para crear productos turísticos}

Esta tercera categoría es sin lugar a dudas la que más evidencía el poco (o nulo en algún caso) apego a la actividad enoturística de estas bodegas.

En primer lugar, destaca el hecho ya comentado del escaso compromiso con la Ruta del Vino. Tal y como se apuntaba anteriormente, ninguno de los miembros de la ruta proporciona información sobre la misma. Este resultado es, cuanto menos, el más insólito del estudio, ya que las propias bodegas, que son las que más van a ganar con la promoción de la ruta, ni siquiera se refieren a su existencia en sus sitios web. La única promoción que se realiza de la misma está en manos del Patronato de Turismo del Priorat, quién se encarga de la promoción, la distrucición y la propia gestión.

Tampoco, ninguna de las bodegas proporciona enlaces a las páginas web de los demás miembros de la ruta. De manera que no se crea un sistema en red que permita aprovechar sinergias, en donde todos los miembros cooperen a la vez que compiten. Amaro et al. (2010) consideran que los enlaces a los otros socios miembros de la ruta, reforzarían la reputación de la empresa y la fiabilidad de la red.

En tercer lugar, se analizó si las webs proporcionan información turística de la zona e incluyen enlaces a las principales atracciones locales, alojamientos y restaurantes. Con la excepción de Bodegas Torres, ninguno de los miembros ofrece información turística. De hecho, Torres tiene un enlace denominado «Centros de interés cercanos», donde se explica la historia y el entorno de Siurana (el pueblo de la bodega); y un enlace denominado «Ocio y Turismo» que proporciona información sobre alojamiento, gastronomía, ocio y naturaleza en la región. También, ofrece un link a la página web de la Oficina de Turismo del Priorat. 
Finalmente, se estudiaron y analizaron las actividades turísticas organizadas por las propias bodegas. Solo el $28 \%$ de las webs ofrece información sobre las actividades que organizan, destacando en la mayoría de casos (96\%) las visitas guiadas, ya sea con o sin reserva. Con el fin de analizar las características de estas visitas se consideraron los siguientes aspectos: (a) qué incluyen, (b) horarios y necesidad de reservar con antelación, (c) precios, (d) número mínimo y máximo de personas por grupo, y (e) idioma/s utilizados. Los resultados evidencían:

- Por norma general, la visita incluye una visita guiada a la bodega y/o viñedos, y una degustación de vinos. El 16\% de bodegas detalla esta información.

- En cuanto a los horarios hay una gran variedad y diversidad. De manera que no hay criterios homogeneos entre bodegas. Algunas están abiertas solo de mañanas, otras de tardes, otras en horarios partidos, otras solo abren al público con reserva previa.

- Relacionado a la necesidad de reservar previamente a la visita, en el $48 \%$ de las empresas se solicita reserva previa solo en días específicos (fin de semana o períodos concretos del año); en el otro $40 \%$ siempre se requiere de una pre-reserva; y solo en el $12 \%$ de las bodegas no es necesario reservar a excepción de la temporada de cosecha (septiembre y octubre).

- Los precios también varían entre las diferentes bodegas, oscilando entre $6 €$ y $10 €$. Sin embargo, el $12 \%$ de las bodegas ofrecen visitas gratuitas, y solo el $8 \%$ de las bodegas discrimina precios en función de la edad, ofreciendo descuentos o entrada gratuita a los menores de edad. Además, algunas bodegas (16\%) ofrecen diferentes precios dependiendo de la actividad turística realizada.

- Acerca del número máximo y mínimo de personas por grupo, casi todas las bodegas (a excepción de una) admiten como mínimo a un solo individuo. En cuanto al máximo por grupo, los resultados son más variables y oscilan entre las 20 y 30 personas. También se identificaron algunos casos extremos de bodegas que acogen a grupos de hasta 300 personas, o que exigen grupos mínimos de 8 o 10 personas.

- En referencia a los idiomas que se usan en las visitas guiadas, todas las bodegas ofrecen visitas guiadas en catalán y español. Además, en el $84 \%$ de los casos también en inglés y el $28 \%$ de bodegas igualmente en francés. Excepcionalmente algunas bodegas también ofrecen visitas guiadas en otros idiomas como alemán, ruso o checo.

En definitiva, los productos turísticos ofertados son generalmente muy básicos y, además, no se promocionan y comercializan a través de sus páginas web. La mayoría se centran en la visita a la bodega, los viñedos y una degustación de vino, y mayormente con reserva previa. Algunas bodegas están empezando a introducir otros servicios turísticos, aunque no es una tendencia generalizada.

Podemos concluir que los resultados globales demuestran que la mayoría de las bodegas tienen páginas web muy estáticas, con una mínima información y, en la mayoría de casos, sin la posibilidad de que el visitante y el administrador puedan interactuar. Esto demuestra que gran parte de las bodegas no discinden el verdadero potencial de Internet como herramienta de marketing (tanto para la promoción y venta de productos y servicios, como para la construcción de una base de datos de clientes reales y potenciales). 
Hay una falta de compromiso real con el turismo del vino por parte de las bodegas de la Ruta del Vino DOC Priorat. Es una evidencia que estas bodegas y viñedos no conciben la actividad turística como una fuente de ingresos real y una oportunidad para promover sus productos. Además, en el caso de la ruta del Priorat no existe una cultura en red efectiva, la connexión entre bodegas solo tiene lugar en el organismo superior (el Patronato). Por esta misma razón, el Patronato de Turismo del Priorat necesita establecer estrategias que le permitan pasar de esta etapa inicial a un estadio de mayor implicación por parte de sus miembros.

Finalmente, querríamos precisar que este estudio se ha concentrado en una sola región en Cataluña, lo que significa que los resultados observados en esta región no son extensibles al resto de regiones vitivinícolas del país, ni a otros destinos a nivel mundial. Sin embargo, hay indicios de que muchos de los resultados son similares a los de otros estudios de casos en regiones donde el enoturismo está en etapas iniciales de desarrollo, pero difieren de los resultados en destinos maduros. 